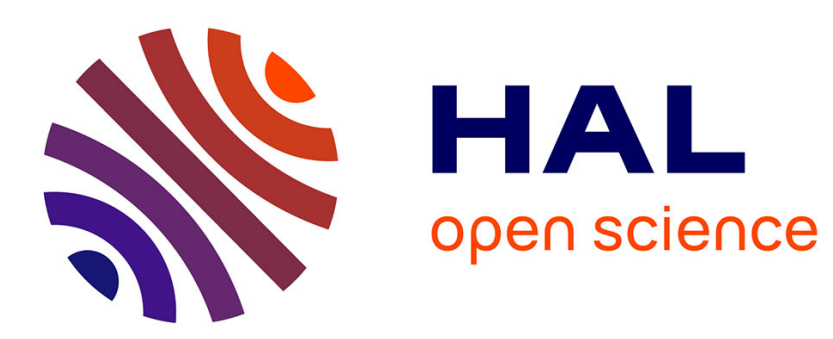

\title{
A composite material used as a membrane for ophthalmology applications
}

E. Stodolak, T. Gumula, R. Leszczynski, J. Wieczorek, S. Blazewicz

\section{To cite this version:}

E. Stodolak, T. Gumula, R. Leszczynski, J. Wieczorek, S. Blazewicz. A composite material used as a membrane for ophthalmology applications. Composites Science and Technology, 2010, 70 (13), pp.1915. 10.1016/j.compscitech.2010.07.007 . hal-00681635

\section{HAL Id: hal-00681635 \\ https://hal.science/hal-00681635}

Submitted on 22 Mar 2012

HAL is a multi-disciplinary open access archive for the deposit and dissemination of scientific research documents, whether they are published or not. The documents may come from teaching and research institutions in France or abroad, or from public or private research centers.
L'archive ouverte pluridisciplinaire HAL, est destinée au dépôt et à la diffusion de documents scientifiques de niveau recherche, publiés ou non, émanant des établissements d'enseignement et de recherche français ou étrangers, des laboratoires publics ou privés. 


\section{Accepted Manuscript}

A composite material used as a membrane for ophthalmology applications

E. Stodolak, T. Gumula, R. Leszczynski, J. Wieczorek, S. Blazewicz

PII:

S0266-3538(10)00264-2

DOI:

10.1016/j.compscitech.2010.07.007

Reference:

CSTE 4761

To appear in:

Composites Science and Technology

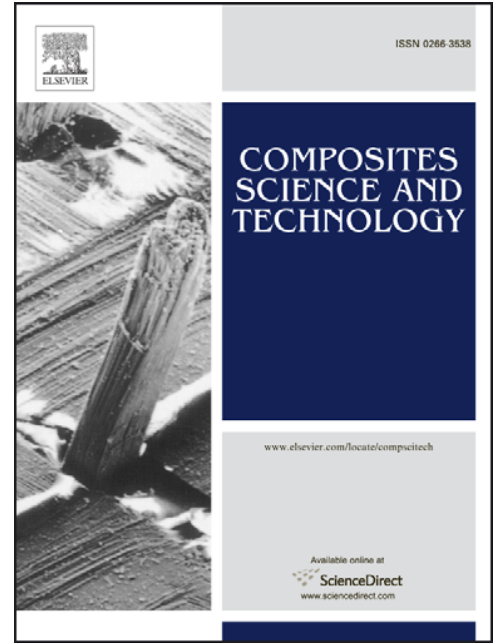

Received Date: $\quad 5$ December 2009

Revised Date: $\quad 14$ May 2010

Accepted Date: $\quad 9$ July 2010

Please cite this article as: Stodolak, E., Gumula, T., Leszczynski, R., Wieczorek, J., Blazewicz, S., A composite material used as a membrane for ophthalmology applications, Composites Science and Technology (2010), doi: 10.1016/j.compscitech.2010.07.007

This is a PDF file of an unedited manuscript that has been accepted for publication. As a service to our customers we are providing this early version of the manuscript. The manuscript will undergo copyediting, typesetting, and review of the resulting proof before it is published in its final form. Please note that during the production process errors may be discovered which could affect the content, and all legal disclaimers that apply to the journal pertain. 
A composite material used as a membrane for ophthalmology applications

E. Stodolak ${ }^{1}$, T. Gumula ${ }^{1}$, R. Leszczynski ${ }^{2}$, J. Wieczorek ${ }^{3}$, S.Blazewicz ${ }^{1}$

${ }^{1}$ Department of Biomaterials, Faculty of Materials Science and Ceramics, University of Science and Technology, Krakow, Poland

${ }^{2}$ Department of Ophthalmology, Medical University of Silesia, Katowice, Poland

${ }^{3}$ Department of Biotechnology of Animal Reproduction, National Research Institute of Animal Production, Balice, Poland

\begin{abstract}
New biomaterials for intracorneal ophthalmologic implants were designed, manufactured and characterized. A composite material in the form of a membrane was manufactured in a two-stage process. The first stage of the process depended on preparation of multidimensional (MD-type) fibrous polymer composite. A stable terpolymer polytetraflouroethylene-co-polyvinylene fluoride-co-polypropylene (PTFEPVDF-PP) was used as a composite matrix, and sodium alginate-based biopolymer (NA) in the form of short fibres and/or powder were used as porogenic constituents. The composite materials were subjected to physicochemical treatment in order to remove a water soluble biopolymer. The treatment led to about $50 \%$ of open porosity within the polymer matrix. Depending on the membrane type the mean pore size determined with SEM microphotographs was 15 to $25 \mu \mathrm{m}$. Permeability and durability of the membranes in simulated eye fluid (culture medium enriched with albumin) was tested. The size and shape of the pores before and after the permeability test were compared (SEM), and they depend on the porogen form. Mechanical parameters of the composite materials such as; tensile strength, Young's modulus, and strain to failure were measured. A membrane derived from fibres and particles showed better mechanical properties than a membrane derived from porogen particles. Microstructure and mechanical properties make the membranes a good candidate for ophthamological implants.
\end{abstract}


Keywords: polymer-matrix composites (PMCs), short-fibre composites, mechanical properties, porosity, casting

\section{Introduction}

Glaucoma is a group of eye diseases characterized by an increase in intraocular pressure that may lead to pathological changes in the optic nerve and subsequently to the vision loss and blindness. Most patients with glaucoma require only medications to control the eye pressure. When medicine therapy fails in lowering the eye pressure a surgery is required. It often involves the use of laser treatments or membrane implants. The objective of any glaucoma surgery is to enable the eye fluid to circulate within the eye easier. Worldwide, it is estimated that about 6.9 million people have visual impairment from glaucoma, and 6.7 million suffer from blindness [1]. The main role of implants in glaucoma treatment is lowering the internal eye pressure by improving the flow of an aqueous humour from inside of the eyeball. Such the membrane implants should facilitate filtration after the surgical treatment $[2,3]$.

The requirements for any material used for ophthalmologic implants are in general sense the same; the material must be biocompatible, biostable and should have the microstructure suitable for fluid transport [4,5]. Such implants are to date made of natural polymers, e.g. collagen, hiauronians or synthetic polymers, e.g. expanded polytetraflouroethylene (e-PTFE), polypropylene (PP), silicones. The main drawback of resorbable membranes made from collagen or hiauronians, is their instability and low permeability [6]. On the other hand, such materials are characterized by good biocompatibility and are able to mimic the structures of natural tissues. For a long-term use the materials applied for the cornea permanent implants have to withstand static and dynamic pressure changes, and be stable in biological environment [7]. In order to 
ensure the proper fluid permeability an ophthalmologic membrane should display an optimum interconnected pore system, total porosity and the mean pores size. Too small pores may be easily blocked by molecules present in the aqueous humour, while larger pores may undergo deformation due to high intraocular pressures [7,8]. The optimal membrane permeability may be obtained for various combinations of pore size and total porosity. Typical pore size for synthetic polymer membranes is in the range of few micrometers to $100 \mu \mathrm{m}[9]$.

Composite materials are more and more frequently used for design and production of implant materials in the wide range of biomedical applications [10-12]. They acquired usefulness due to their capability of controlling mechanical properties of the pure polymers and adjusting them to the properties of the damaged tissue. The composites having differently oriented fibrous reinforcement component (1D, 2D, 3D and MD) within the matrix can be used to fabricate load-bearing implants for bone surgery [13-16]. The proper design and choice of the composite constituents for ophthalmologic biomaterials enable to obtain a biomimetic structure similar to the natural tissue required for filtration of the nourishing fluid flow into and out of the eye, i.e. drainage channel. In the case of MD composite the effective dispersion of the short fibres in a polymeric matrix enables modification of the whole volume of the material and ensures creation of a continuous fibres network [17]. The suitable selection of the fibrous phase as a porogen and further physicochemical treatment of the composite material enables the formation of interconnected pores within the material [18]. Such a material may be an alternative for commonly used polymer materials.

The aim of this work was to elaborate a biocompatible composite membrane that can be used in the glaucoma treatment. Microstructure, mechanical parameters and 
biocompatibility of the materials in the form of membrane were optimized. The effect of a simulated biological environment on the elaborated composite materials was investigated. The membrane was made of a stable synthetic polymer, i.e. PTFE-PVDFPP constituting a composite matrix, and a fibrous phase made of sodium alginate being a water soluble porogenic component for the creation of the desired porosity in the polymer matrix. PTFE-PVDF-PP terpolymer was chosen for a matrix due to its suitable mechanical properties (flexibility, creep behaviour, tensile strength and durability), biocompatibility, surface physicochemical properties, i.e. hydrophobicity and easier processability comparing to its pure polymer constituents, particularly to PTFE. The terpolymer was successfully used in other biomaterial applications [18-23].

The study was devoted to preparation and characterisation of the membrane materials having suitable mechanical and fluid transport properties in the implant site.

\section{Materials and methods}

PTFE-PVDF-PP terpolymer (Aldrich Chemical Co., USA) and sodium alginate (Biopolymer, AS Protanal LF 20/60, with dominating blocs of guluronic acid, $65 \%$, Norway) were used to prepare the composite membranes. Molecular weight of the terpolymer from solution viscosity measurements was approx. $300 \mathrm{kDa}$. A $1 \% \mathrm{w} / \mathrm{v}$ solution sodium alginate in water has a viscosity at $20^{\circ} \mathrm{C}$ of $1,2 \mathrm{cP}$. Two types of composite materials were made. The first type was prepared by using $2 \mathrm{wt}$. \% of sodium alginate (NA) in the form of a powder. The second type of samples was prepared by using 2 wt. $\%$ of sodium alginate in the form of two-fraction additive, i.e. short fibres and small particles (NA powder). The two-fraction additive was prepared by grinding of short alginate fibres in a rotating mill. The aim of the fibres fragmentation was to improve their ability to create a continuous interconnected pore network in the 
membranes. The alginate fibres were prepared by Department of Man-Made Fibres of Technical University in Lodz using the wet method described elsewhere [24].

Weighted amounts of the porogen $(2 \mathrm{wt} . \%)$ were mixed with the polymer solution (acetone, 1:10). Then the mixture was poured on a Petri dish and dried at ambient temperature for $48 \mathrm{~h}$ in order to evaporate the solvent and finally the samples in the form of thin foils were obtained. In order to remove the porogen and to create open porosity within the materials the polymer foils were incubated in distilled water at $80^{\circ} \mathrm{C}$ for $84 \mathrm{~h}$. The scheme of preparation of the composite membranes differing in the porogen component is shown in the Fig 1. Using this method two kinds of membranes were manufactured; M1 - a membrane derived from the composite containing NA particles only (NA powder), M2 -a membrane derived from the composite containing NA fibres and the particles (NA powder) prepared by additional fragmentation (grinding) of the fibres.

The porogen morphology, i.e. sodium alginate fibres/particles was studied under SEM (Jeol 5400). Particle size distribution of the powder was determined by DLS method (Nanosizer-ZS), and fibres size (diameter, length) was measured with the optical microscope (Lanametr, PZO, Poland).

Permeability of the membranes in static conditions was tested by measuring the electrolytic conductivity of distilled water separated by the membrane from $\mathrm{NaCl}$ solution $\left(0.1 \mathrm{M} \mathrm{NaCl} / 37^{0} \mathrm{C} / 3\right.$ weeks $)$.

Permeability of the membranes was investigated using a special test device allowed to simulate variable pressure conditions (dynamic mode) inside the eye. The eye simulator device illustrated in Fig.2 was designed to compare changes in the membranes subjected to intraocular pressure in a normal eye and the pressure existing 
in an eye with glaucoma disease. During the experiments the test device consisted of piston (driven by an electric motor) pumped the fluid through the membrane to simulate pressure conditions taking place during a severe attack of glaucoma, i.e. the cyclic pressure exerted on the membrane was in the range of $0-55 \mathrm{mmHg}\left(5 \mathrm{~h} / 37^{\circ} \mathrm{C}\right)$. As a biological environment a bovine serum modified with $5 \%$ of albumins was used (SEF). Like in a case of the static conditions, the membrane was placed between two chambers - one filled with distilled water and the second one filled with the serum.

The permeability was determined by measuring the ionic conductivity and $\mathrm{pH}$ of the serum. After the tests in the eye simulator, the membranes microstructure and their thickness were measured. Mechanical properties of the composite samples and membranes, namely tensile strength $\left(\mathrm{R}_{\mathrm{m}}\right)$, Young's modulus $(\mathrm{E})$, elongation at the maximum force $\left(\varepsilon \mathrm{F}_{\max }\right)$, and work up to failure $(\mathrm{W})$ were measured using an universal testing machine Zwick 1435.

All presented results are an average from five measurements, and the error was estimated basing on t-Student test at significance level of 0.05 .

\section{Results}

The microscopic observw3ations of the sodium alginate short fibres after grinding (fragmentation) in the laboratory rotating mill indicate that the fibrous phase consisted of short fibres (diameter of $0.17 \pm 0.05 \mu \mathrm{m}$, length of $1.50 \pm 0.28 \mathrm{~mm} ; 95 \%$ of the population), and much smaller particles (diameter of $0.75 \mu \mathrm{m} ; 5 \%$ of the population), which were products of their fragmentation (Fig.3). Diversification of the porogen particles sizes ensures the formation of the network of interconnected pore system. The pore sizes in polymer matrix correspond to the sizes of the fibres and products of their fragmentation. The alginate powder used as a porogen in the other 
membrane type consisted of particles with similar sizes (Fig.3, diameter $0.45 \div 0.75 \mu \mathrm{m}$ ), which were the origin of pores of analogous characteristics.

After removal of the porogen components (powder, fibres) both membranes exhibited surface porosity and similar thickness of about $180-200 \mu \mathrm{m}$. Alginate fibres and powder - based membrane (M1) exhibits two types of pore fractions, i.e. large, elliptical pores formed by washing out the fibrous porogen (small amount), and round and small in size pores formed by washing out the NA powder (larger amount). Microphotographs of the cross-section areas of the membranes revealed that distribution of pores was uniform in whole volume of samples (Fig.4). A well-developed system of interconnected pores was particularly visible in the case of M2 membrane, in which the porogen consisted of a mixture of fibres and particles of a different size. The presence of the interconnected pores was confirmed by ion conductivity test performed in static conditions (Fig.5).

A qualitative analysis of several microphotographs revealed that both membranes have similar porosity, slightly higher for M1 membrane (c.a. 54\%) as compared to M2 membrane (c.a. $49 \%$ ). The estimated mean pore size of the membrane surface was close to the size of the removed porogen particles/fibres and corresponded to c.a. $25 \mu \mathrm{m}$, and c.a. $15 \mu \mathrm{m}$ for M1 and M2 membranes, respectively. These values of pore sizes make the membranes suitable for transport of aqueous humour containing macromolecules of proteins such as albumin and inorganic salts.

Such pores do not affect permeability of ions, and the changes of ion conductivity observed during the static test (Fig.5) may be attributed to removal of porogen particles/fibres which were not fully washed out during the membrane fabrication. The differences between the residual porogen in M1 and M2 membrane resulted probably 
from the difference in the form of the porogen. Relatively larger fibrous porogen present in M2 membrane was washed out faster and after 4 days the conductivity remained constant. Increasing ion conductivity in the case of M1 membrane indicated that smaller porogen particles were constantly washed out during the test.

A test performed in static conditions revealed that $\mathrm{Na}^{+}$and $\mathrm{Cl}^{-}$ions migrated through M1 membrane faster, which may be related to its a higher pore size and a better developed network of interconnecting pores (Fig.5).

Permeability of the membranes was investigated in dynamic in vitro experiment using the set-up to simulate pressure conditions and fluid transport in the eye (Fig.2). The membrane placed in the chamber with the simulated eye fluid (SEF): bovine serum containing albumins was subjected to variable pressure loading $(0-55 \mathrm{mmHg})$. Despite relatively high pressure exerted on the membranes they did not lose their permeability which indicates, that the pores were not blocked by the protein molecules, and the fluid circulation was not hindered. Also the ion conductivity of the solution used to verify the permeability remained at the same level during the whole time of the experiment (Fig.6). The runs of conductivity measurements shown in Fig.6 for water and bovine serum confirm the stable fluid transport through the membranes.

Both membrane materials were stable in in vitro conditions since no chemical and physical changes were observed after 24 months of incubation in water at $37^{\circ} \mathrm{C}$. These preliminary results indicate that the membrane materials studied may find application as permanent implants in glaucoma treatment.

The mechanical tests of the membranes showed inferior mechanical properties in comparison with the pure polymer foil (the reference sample). In the case of the membranes the decrease in tensile strength $\left(R_{m}\right)$, Young's modulus $(E)$, work to failure 
(W), and strain to failure $\left(\varepsilon \mathrm{F}_{\max }\right)$ were observed, Table 1 . These changes resulted from higher porosity of the membrane materials.

Dynamic tests performed on the membranes subjected to constant and variable pressures indicated that initially determined mechanical properties did not change after the test. Moreover, the shape and diameter of the pores were stable. The membrane thickness remained stable after the tests simulating an eye environment. Changes in microstructure of the membranes under the applied load were negligible and did not influence their permeability.

The mechanical fatigue properties of the membranes were tested under static and dynamic pressure loads. The average diameter of pores was higher than that observed in membrane materials without pressure loading, i.e. 30-35 $\mu \mathrm{m}$, and 35-40 $\mu \mathrm{m}$ for M1 and M2 membrane, respectively. Neither of the membranes was fractured nor damaged after the fatigue mechanical tests.

\section{Conclusions}

Application of water soluble sodium alginate fibres for polymer modification is a useful method for the preparation of a membrane material with a controllable pores microstructure. The membrane material based on the sodium alginate fibres showed the highest strain to failure and an enhanced tensile strength. The lack of physical changes observed in in vitro conditions suggests that the membranes are stable.

Both types of the membranes performed a relatively high strength and elasticity (high strain to failure), which make them suitable for planned application. Time test simulating an eye environment (fluid, pressure) demonstrated that the elaborated materials did not loss their properties. It may be expected that such membranes will be suitable for a long-term performance implant. The obtained data, however indicate that 
further study should be continued to evaluate the manufactured glaucoma implant on in vivo model. M2 material is a better candidate for a membrane for glaucoma treatment due to its mechanical properties, sufficient pore size and fraction, possibility for removing completely the porogen as well as stability of the mechanical characteristics in in vivo conditions.

\section{Acknowledgements}

This work was supported by The Polish Ministry of Science and Higher Education, grant No. N518 028 32/1769. Ewa Stodolak is a beneficent of programme START of Foundation for Polish Science in 2009.

\section{References}

[1] Eldaly M, Anand N, Bunce C, Khafagy M, Non-penetrating filtration surgery versus trabeculectomy for open angle glaucoma, Cochrane Database of Systematic Reviews 2008, Issue 2. Art. No.: CD007059. DOI: 10.1002/14651858.CD007059

[2] Nuengjamnong C, Kweon JH, Cho J, Polprasertc C, Ahn K.-H, Membrane fouling caused by extracellular polymeric substances during microfiltration processes, Desalination, 2005; $179 ; 117-124$

[3] Nizankowska M, Kaczmarek R, Prevalance of open angle glaucoma and ocular hypertension as a risk factor for primary open angle glaucoma in Wroclaw population, Wroclaw Epidemiological Study 106; 2004; 1-2; 106-132

[4] Shaarawy T, Nguyen C, Achache F, Comparative study between deep scleretomy with and without collagen implant: long term follow-up, Br J.Ophthalmol, 88; 2004; 1; 95-98

[5] Wevill MT, Meyer D, van Aswegen E, A pilot study of deep sclerectomy with implantation of chromic suture material as a collage implant: medium - term results, Eye, 19; 2005; 549-554 
[6] Chiou AGY, Mermoud A, Underdahl JP, Schnydrer CC, An Ultrasound Biomicroscopic Study of Eyes After Deep sclerectomy with Collagen Implant, Ophthalmology 105; 1998; 125 136

[7] Shaarawy T, Nguyen C, Achache F, Comparative study between deep scleretomy with and without collagen implant : long term follow-up, British J.Ophthalmol, 88; 2004; 1; 95-98

[8] Kontturi K, Vuoristo M, Adsorption of globular proteins on polymeric microfiltration membranes, Desalination 104; 1996; 1-2; 99-105

[9] Zalewska R, Mariak Z, Kraśnicki P, Proniewska-Skretek E, Non-penetrating deep sclerectomy with SK-GEL implant in the patients with pseudoexfoliation glaucoma, Klin Oczna. 2004;106(1-2 Suppl):173-5

[10] Ramakrishna S, Mayer J, Wintermantel E, Leong KW, Biomedical applications of polymer-composite materials: a review, Composites Science and Technology, 61; 2001; 36; $1189-1224$

[11] Feng Z, Yuji Y, Chiyan L, Wenyi Z, Jingyu Z, Preparation and histological evaluation of biomimetic three-dimensional hydroxyapatite/chitosan-gelatin network composite scaffolds, Biomaterials $23 ; 2002 ; 3227-3234$

[12] Toshihiro K, Yoshio O, Masayuki N, Yoshihiro A, Preparation and mechanical properties of polylactic acid composites containing hydroxyapatite fbers, Biomaterials 22; 2001; 19-23

[13] Blazewicz S, Chlopek J, Litak A, Wajler C, Staszków E, Experimental study of mechanical properties of composite carbon screws, Biomaterials 18; 1997; 5; 437-439

[14] Gasser B, About composite materials and their use in bone surgery, Injury, Int. J. Care Injured $31 ; 2000 ; 48-53$

[15] Fujihara K Huang, Zheng-Ming, Ramakrishna S, Satknanantham K, Hamada H, Performance study of braided carbon/PEEK composite compression bone plates, Biomaterials $24 ; 2003 ; 15 ; 2661-2667$

[16] Gross A, Rodríguez-Lorenzo L, Biodegradable composite scaffolds with an interconnected spherical network for bone tissue engineering, Biomaterials 25; 2004; 20; 4955-4962 
[17] Xie E, Hu Y, Chen X, Bai X, Li D, In vivo bone regeneration using a novel porous bioactive composite, Applied Surface Science 255; 2008; 2; 545-547

[18] Stodolak E, Zaczynska E, Błażewicz M, Wołowska-Czapnik D, Leszczyński R, Membrane composite materials for medical application - primary material and biological study Composites 6; 2006; 4; 47-52

[19] Zaczyńska E, Czarny A, Żywicka B, Stodolak E, Błażewicz M, The study of cytotoxity of fibrous composite materiale, Engineering of Biomaterials, 58-55; 2005; 20-23

[20] Stodolak E, Czajkowska B, Błażewicz M, Mikołajczyk T, Wołowska-Czapnik D, In vitro behavior of PP-PVDF-PTFE terpolymer modified with alginate fibres, Engineering of Biomaterials, 38-43; 2004; 208-211

[21] Blazewicz M, Stodolak E, Wilk P, Czapnik-Wolowska D; Fibrous, bioactive composite materials for bone regeneration, Proceedings and Monographs" Polish Academy of Sciences Vienna 6; 2006; 148-149

[22] Stodolak E, Czajkowska B, Mikołajczyk T, Błażewicz M, Wołowska-Czapnik D; The effect of surface parameters of fibrous composite materials on cellular response, Engineering of Biomaterials, 58-55; 2005; 28-31

[23] Stodolak E, Krok M, Gumuła T, Błażewicz S, Composite membranes materials for ophthalmological implants, Composites 9 (2009) pp. 352-357

[24] Bogun M; Rheological, Properties of Sodium Alginate Spinning Solutions with Ceramic Nanoadditives. Fibres and Textils in Eastern Europe 17; 2009; 5 (76) pp. 17-22 
Tabel 1. Mechanical properties of membrane materials: M1 and M2

\begin{tabular}{c|cccc}
\hline Material & $\mathbf{R m}[\mathbf{M P a}]$ & $\boldsymbol{\varepsilon}$ Fmax [\%] & E [MPa] & W [J] \\
\hline Membrane M1 & $0.28 \pm 0.06$ & $258 \pm 39$ & $0.12 \pm 0.06$ & $0.22 \pm 0.06$ \\
Membrane M2 & $0.35 \pm 0.02$ & $485 \pm 45$ & $0.19 \pm 0.04$ & $0.37 \pm 0.08$ \\
\hline Polymer foil & $0.5 \pm 0.06$ & $726 \pm 53$ & $0.49 \pm 0.14$ & $0.41 \pm 0.03$ \\
\hline
\end{tabular}

$* \mathrm{R}_{\mathrm{m}}$ - tensile strength, $\varepsilon \mathrm{F}_{\max }-$ elongation at the maximum force, $\mathrm{E}-$ Young's modulus, $\mathrm{W}$ - work up to break 


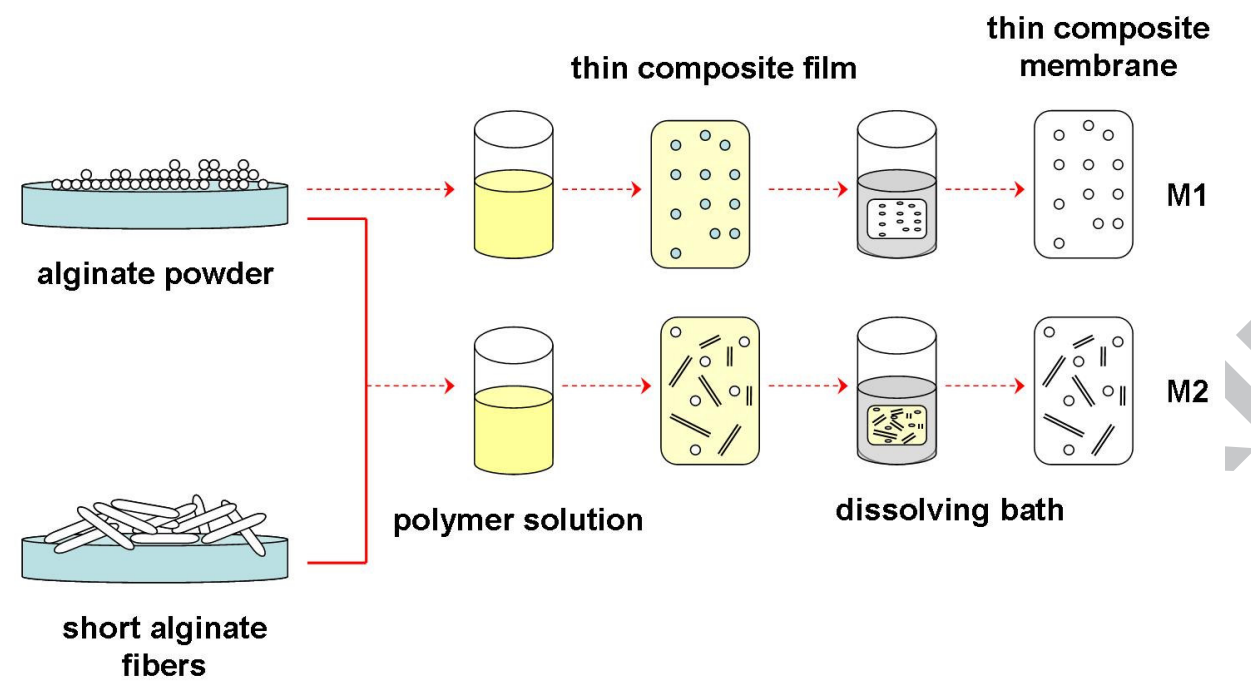

Fig 1. Schema of preparation of composite membrane M1 and M2 

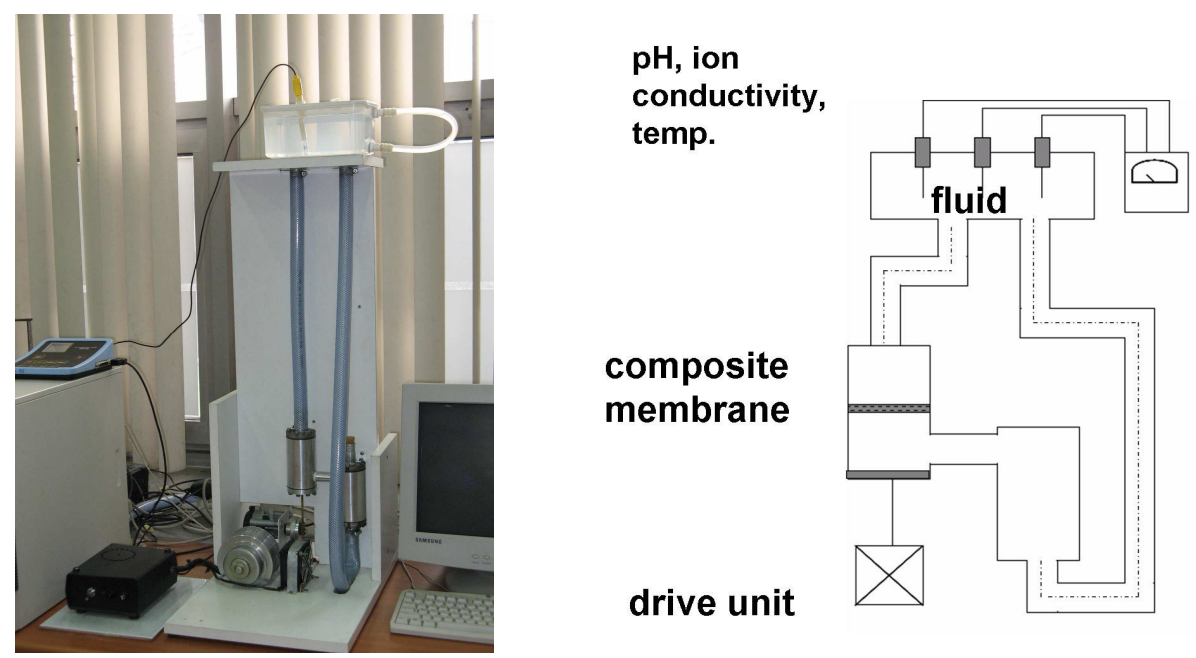

Fig 2. Set-up used for testing permeability of membrane 

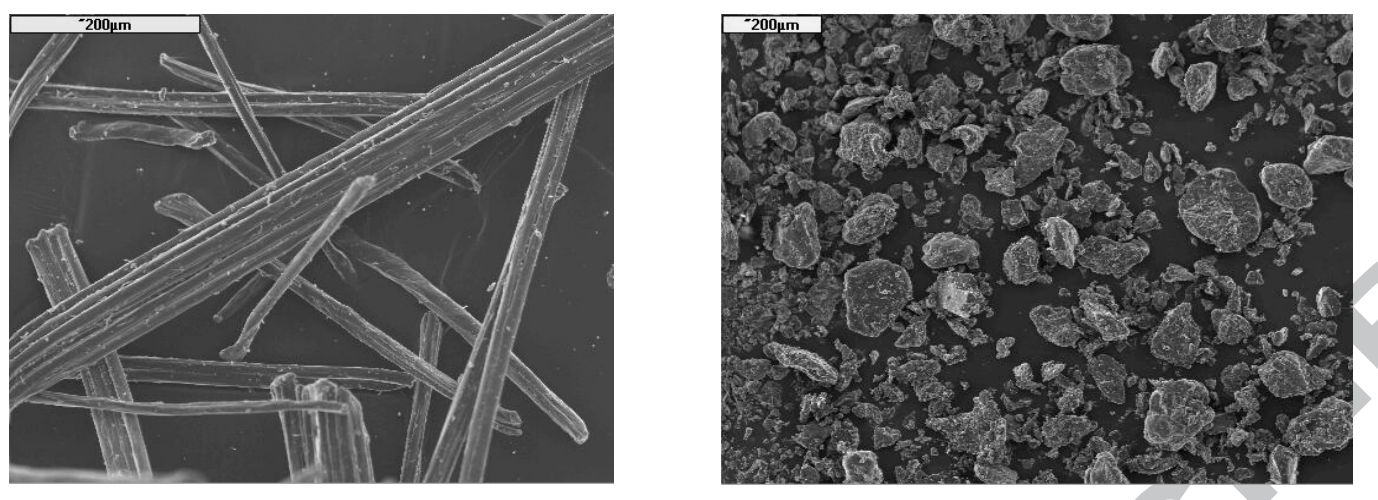

Fig 3. SEM microphotographs of the porogens; sodium alginate fibres (NA), sodium alginate powder (NA) 

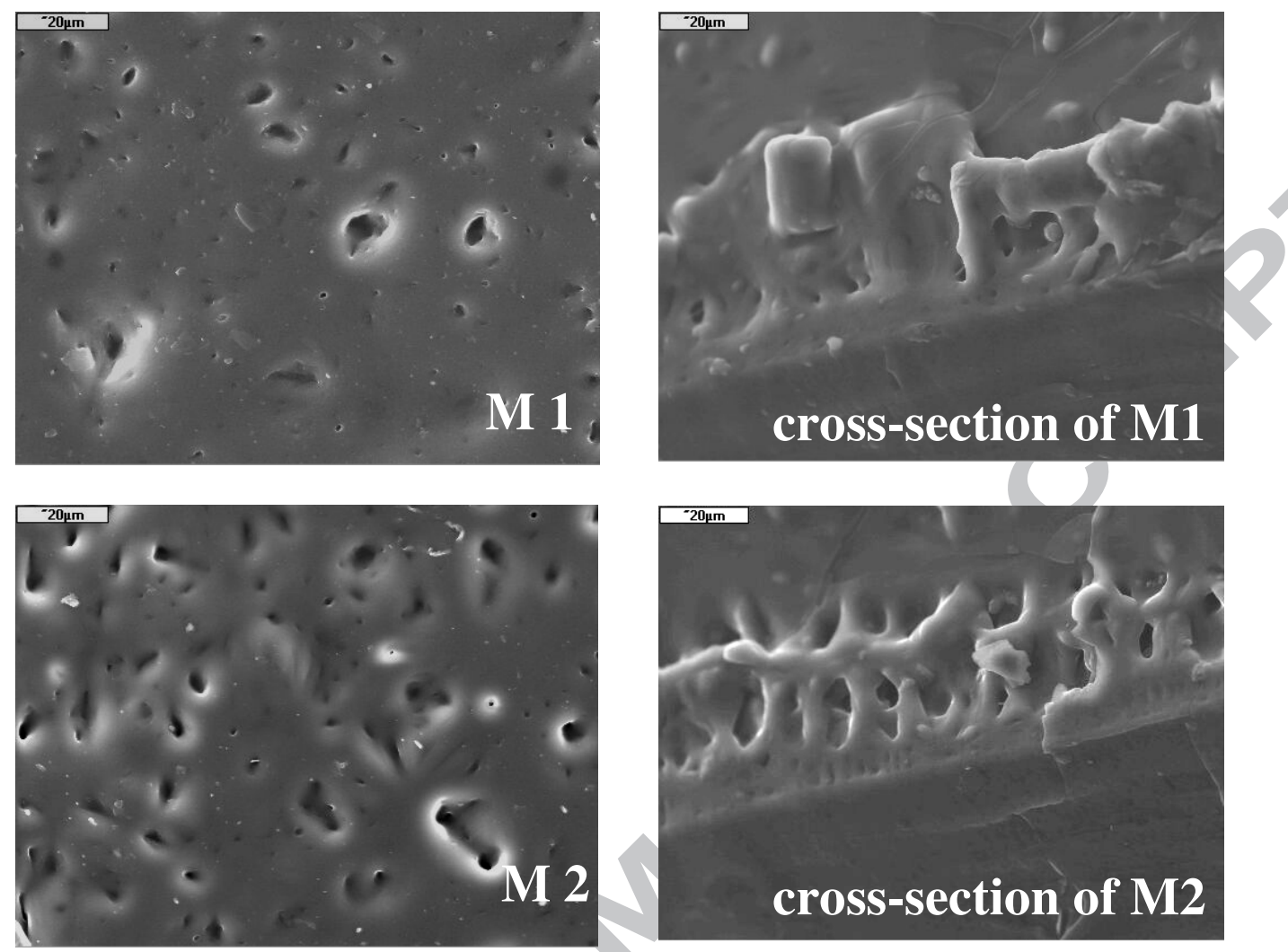

Fig 4. SEM microphotographs of membrane surfaces: M1 - NA- based membrane, M2NA fibres and powder- based membrane 


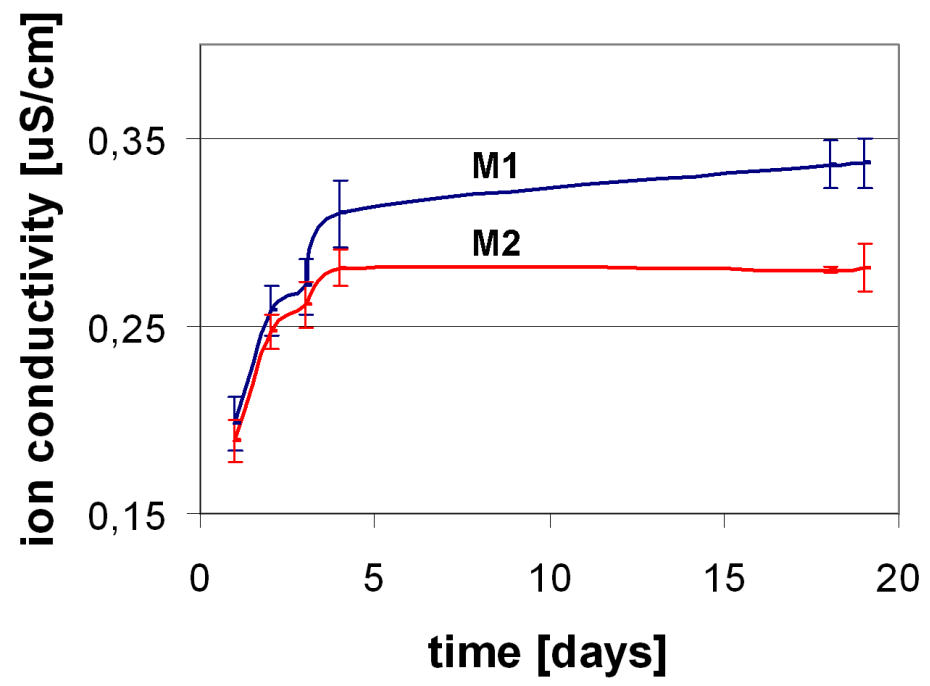

Fig 5. Permeability test of the membranes in static conditions $\left(0.1 \mathrm{M} \mathrm{NaCl} / 37^{0} \mathrm{C} / 3\right.$ weeks). Variations of the ionic conductivity of distilled water separated from $\mathrm{NaCl}$ solution with membrane 

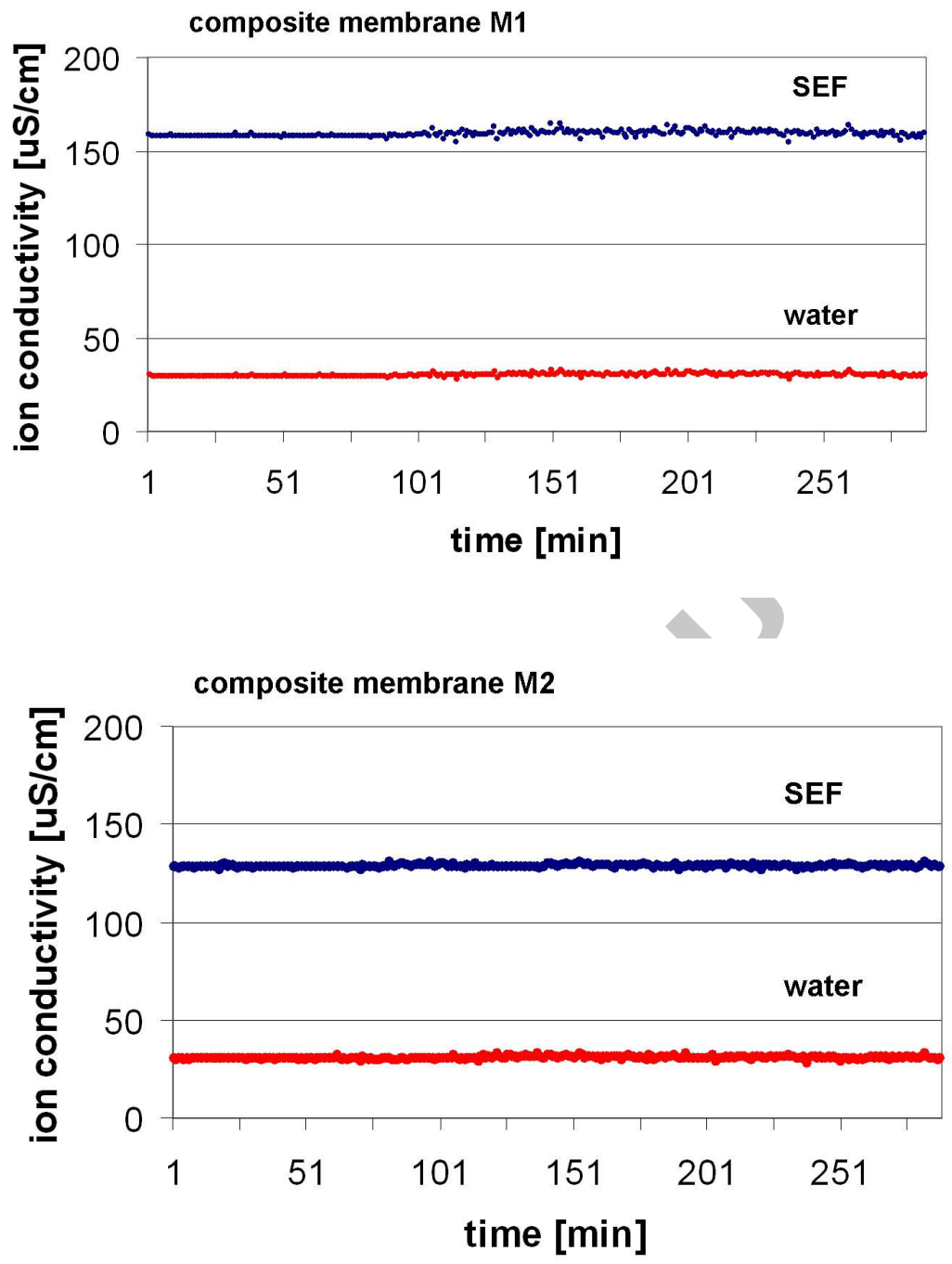

Fig 6. Permeability of membranes; M1 and M2 during fluid flux through the membrane in dynamic mode (water $37^{\circ} \mathrm{C} / 7$ days, or SEF $/ 37^{\circ} \mathrm{C} / 7$ days) 


\section{ACCEPTED MANUSCRIPT}

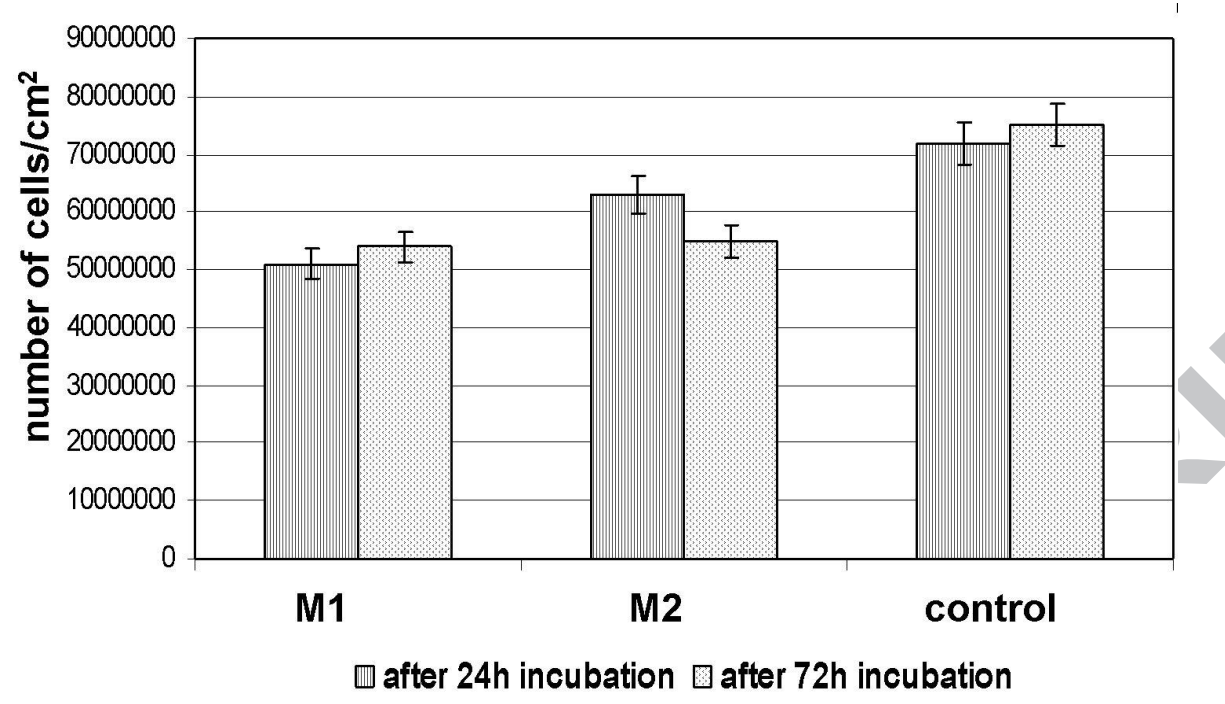

Fig 7. Number of cells present on the surface of composite membrane M1 and M2 